\title{
Study of etiopathogenesis and clinical profile of patients presenting with abnormal uterine bleeding
}

\author{
Namrata Yeole*, Arun H. Nayak, Madhuri Mehendale
} Department of Obstetrics and Gynecology, Lokmanya Tilak Municipal Medical College and General Hospital, Sion,
Mumbai, Maharashtra, India

Received: 06 August 2019

Revised: 15 November 2019

Accepted: 19 November 2019

\section{*Correspondence:}

Dr. Namrata Yeole,

E-mail: namratayeole@gmail.com

Copyright: () the author(s), publisher and licensee Medip Academy. This is an open-access article distributed under the terms of the Creative Commons Attribution Non-Commercial License, which permits unrestricted non-commercial use, distribution, and reproduction in any medium, provided the original work is properly cited.

\section{ABSTRACT}

Background: AUB is a common condition affecting $14-25 \%$ of women of reproductive age and may have a significant impact on their physical, social, emotional and material quality of life. AUB can occur at any age in various forms and has different modes of presentation. The key to successful clinical management is to recognize or identify the causative factors responsible.

Methods: This study was conducted over 100 patients. Patients with complaints of menstrual irregularity between menarche to premenopausal age group were considered. Data about age, parity, menstrual history, obstetric history, medical history, physical examination, thyroid function test, radiological findings and histopathology were collected and studied.

Results: Incidence of AUB is more common in 5th decade of life. Menorrhagia is the most common bleeding pattern. It is concluded that DUB is the most common cause of AUB. Among the other organic pathological causes, fibroid is the commonest. Maximum number of apparently normal patients with abnormal uterine bleeding belong to category of sub clinical hypothyroid.

Conclusions: Accurate analysis of endometrial sample is the key to effective therapy and rational approach to treatment of women with abnormal uterine bleeding.

Keywords: Abnormal uterine bleeding, Hypothyroidism, Menorrhagia

\section{INTRODUCTION}

Abnormal uterine bleeding (AUB) may be defined as any variation from the normal menstrual cycle, including alteration in regularity, frequency of menses, duration of flow and amount of blood loss. ${ }^{1}$ It is the most common presenting symptom and major gynecological problem affecting as many as one-third of all out patient gynecologic visit. ${ }^{2,3}$ AUB can occur at any age in various forms with different modes of presentation. Abnormal uterine bleeding during the reproductive age can result from a broad spectrum of conditions ranging from physiological process to malignant lesions involving organic, systemic and hormonal responses.

The International Federation of Gynecology and Obstetrics working group on menstrual disorders has developed a classification system PALM-COIEN for causes of AUB in non-pregnant women of reproductive age. $^{4}$ The classification system is divided into nine categories that are arranged according to the acronym PALM-COEIN: polyp, adenomyosis, leiomyoma, malignancy and hyperplasia, coagulopathy, ovulatory disorders, endometrial, iatrogenic and not classified. Out of all the etiologies, age variation and clinical 
presentation like thyroid dysfunction (subclinical or clinically evident) are becoming important factors associated with AUB. For successful clinical management recognition of the causative factors is important. This can be achieved by thorough clinical examination, ultrasonography and histopathological examination. Abnormal uterine bleeding is initially managed medically. A number of minimally invasive surgical alternatives for hysterectomy are available now such as endometrial ablation, thermal balloon therapy and uterine artery embolisation. ${ }^{5}$ but restricted availability and cost limit them from being used widely. Therefore, hysterectomy still remains the widely accepted and practiced treatment. ${ }^{6,7}$

\section{METHODS}

The present study which is an observational study was conducted at tertiary care centre from June 2016 to October 2017.

\section{Inclusion criteria}

- All cases provisionally diagnosed to have abnormal uterine bleeding from puberty to premenopausal age groups

- All patient having major complaint of menstrual disturbances e.g., menorrhagia, polymenorrhoea, polymenorrhagia, metropathia hemorrhagica, metrorrhagia, oligo and hypomenorrhoea.

\section{Exclusion criteria}

- Patients who are on anticoagulant drugs, IUCD users, history of bleeding disorder will be excluded.

A total 100 sample size were included. This study was conducted from June 2016 to October 2017. Informed consent was obtained from each patient included in the study. Patients with complaints of menstrual irregularity between menarche to premenopausal age group were considered.

\section{Parameters studied}

- Age

- age of menarche

- Secondary sexual characters

- Associated medical disorders

- Family history

- History of any drug intake

- Past history of surgeries/ surgical illness

- General examination

- Systemic examination

- Local examination

\section{Lab investigations}

- $\mathrm{Hb}, \mathrm{CBC}$ and other relevant investigations
- coagulation study

- Thyroid function test

- Radiological investigation

- Histopathology

\section{Menstrual irregularity - types and definitions}

As per the thyroid dysfunction we categorized patients into 4 groups:

- Category 1 (overt hypothyroidism) was defined as an elevated TSH $\geq 10 \mathrm{mIU} / \mathrm{L}$. In women with, irrespective of their FT4 level, were considered as clinical hypothyroidism

- Category 2 (subclinical hypothyroidism) was defined if serum TSH was between 5 to $10 \mathrm{mIU} / \mathrm{L}$ with a normal FT4 concentration

- Category 3 (Euthyroid) was defined as S. TSH levels between $0.4-5 \mathrm{mIU} / \mathrm{L}$

- Category 4 (Hyperthyroid) was defined as S.TSH $<0.4 \mathrm{mIU} / \mathrm{L}$.

\section{Statistical analysis}

Data about age, parity, menstrual history, obstetric history, medical history, physical examination, thyroid function test, radiological findings and histopathology were collected. The data was entered in Microsoft excel 2007 and was analyzed using SPSS version 20.0. Qualitative data was analyzed by using frequency and percentage and quantitative data by mean and standard deviation. Association between two qualitative data was done by chi-square test or fisher exact test. $\mathrm{P}$ value less than 0.05 is considered as significant.

\section{RESULTS}

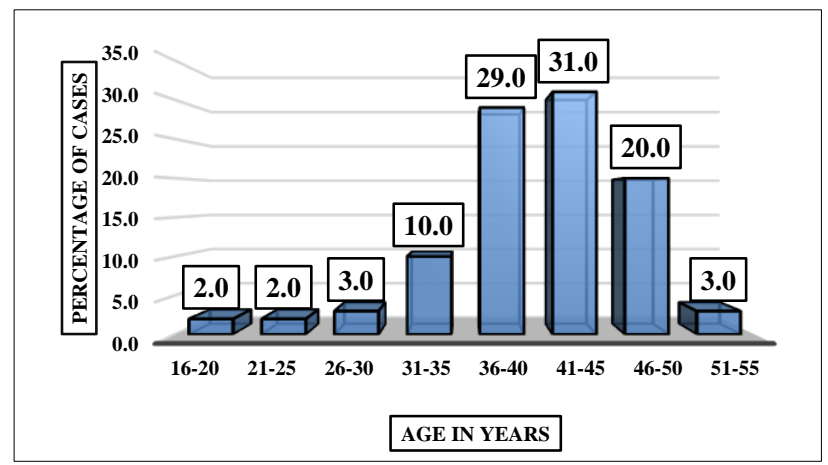

Figure 1: Distribution of cases according to age.

Figure 1 shows incidence of abnormal uterine bleeding between age group 16-55 years. In clinical study, AUB was commonly seen among 41-45 years of age group. $2 \%$ cases are in age group 20-25 years, $3 \%$ cases are in age group 26-30 years, $10 \%$ cases are in age group 31-35 years, $29 \%$ cases are in the age group 36-40 years, $20 \%$ cases are seen in the age group of 46-55 years. 


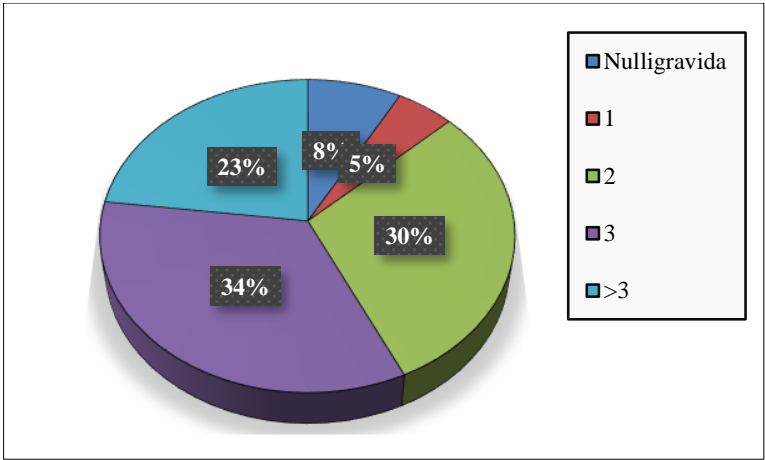

Figure 2: Distribution of cases according to parity.

Figure 2 shows relationship of AUB with parity. Among 100 cases of AUB maximum are with para 3-37 cases $(34 \%)$ and minimum cases are with para1 5 cases $(5 \%)$.

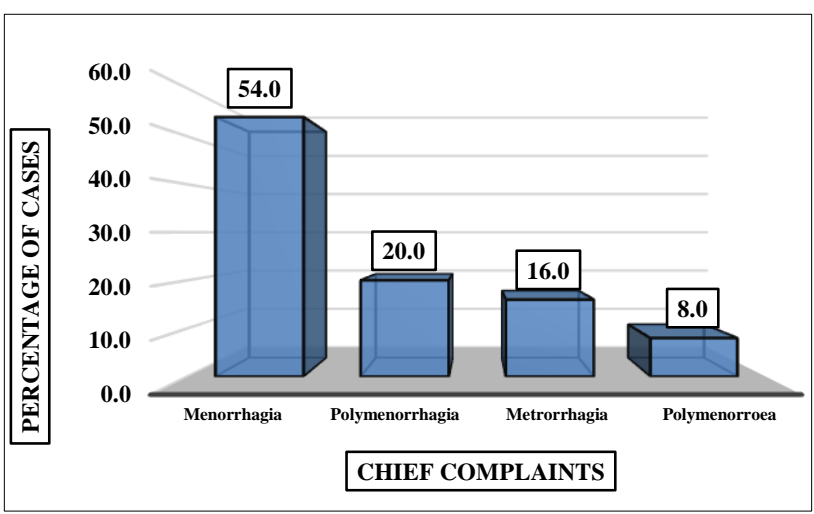

Figure 3: Distribution of cases as per various modes of presentation.

Figure 3 shows 100 patients who came with the complaint of different bleeding pattern. Maximum were seen with complaints of menorrhagia (54\%). Minimum were seen in polymenorrhoea $(8 \%)$.

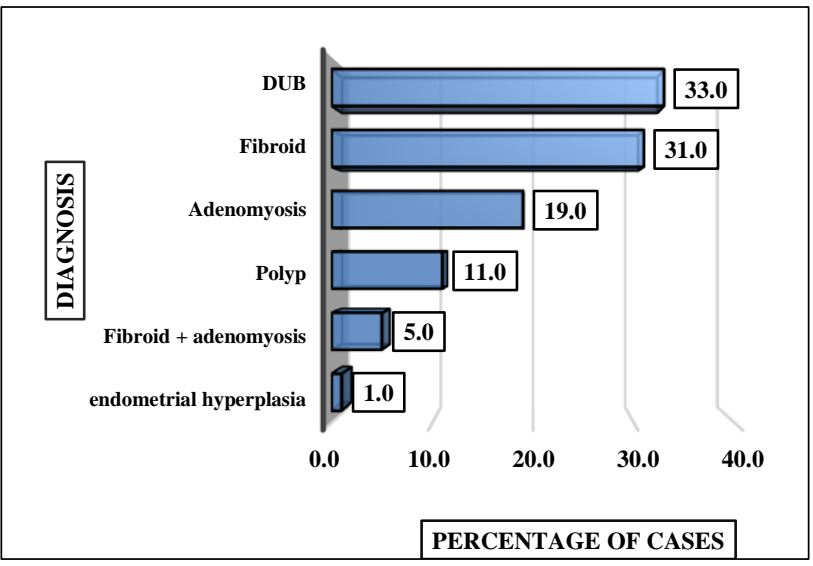

Figure 4: Distribution of cases as per etiology.

Figure 4 shows distribution of cases as per the etiology of AUB. Amongst 100 cases most common cause of AUB is DUB (33\%). Among the other organic pathological causes, fibromyoma $(31 \%)$ is the commonest cause followed by adenomyosis (19\%).

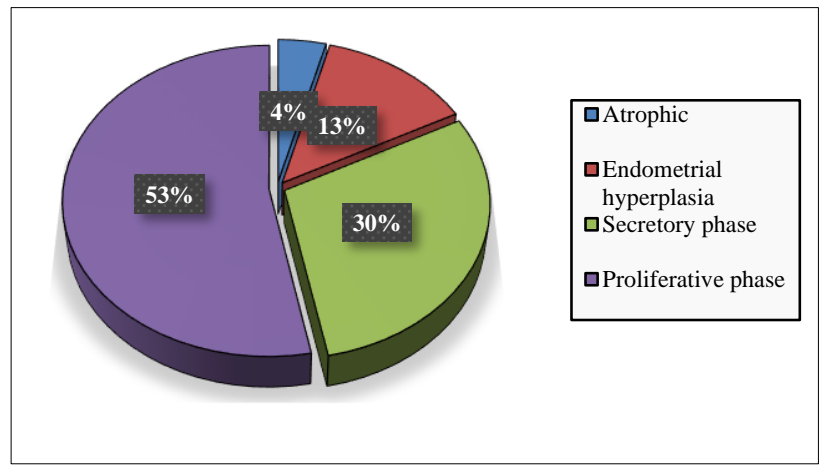

Figure 5: Distribution of cases as per histopathology.

Figure 5 shows different endometrial pattern associated with abnormal uterine bleeding. Out of 100 cases, an endometrial biopsy was done in 98 cases and in 2 cases endometrial biopsy was not done. Proliferative endometrium was found in $52(53.1 \%)$ cases, secretory endometriumin $29(29.6 \%)$ cases, and hyperplastic endometrium in $13(13.2 \%)$ cases. Atrophic endometrium was found in 4 cases.

Figure 6 shows maximum number of apparently normal patients with abnormal uterine bleeding were euthyroid (86\%), sub clinical hypothyroid were (8\%). Profound hypothyroid was present in only $5 \%$ of cases. $1 \%$ of cases had hyperthyroidism.

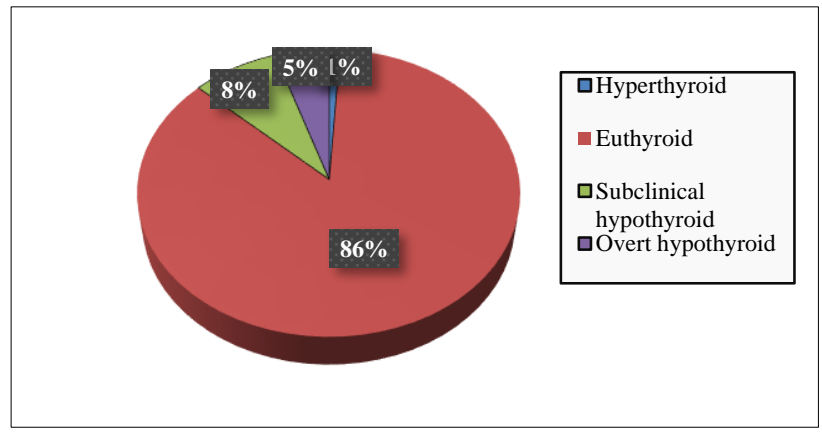

Figure 6: Distribution of cases as per thyroid dysfunction.

Table 1 shows in 16-25 years age group $25 \%$ has subclinical hypothyroidism, in 26-35 years all are euthyroid, in 36-45 years $8.3 \%$ are overt hypothyroid and $10 \%$ has subclinical hypothyroidism, 46-55 years age group $4.3 \%$ has subclinical hypothyroidism. Maximum cases with thyroid dysfunction were seen in the age group of 16-25 years.

Table 2 shows among subclinical hypothyroid cases polymenorrhagia $(50 \%)$ was the most common presentation, among overt hypothyroid menorrhagia (40\%) and among hyperthyroid polymenorrhagia was the most common presentation. 
Table 1: Distribution of cases as per thyroid dysfunction in various age groups.

\begin{tabular}{|lllllll|}
\hline \multirow{2}{*}{ Age in years } & S. TSH & Euthyroid & Hyperthyroid & Overt hypothyroid & Subclinical hypothyroid & Total \\
\hline \multirow{2}{*}{$16-25$} & Count & 3 & 0 & 0 & 1 & 4 \\
\cline { 2 - 7 } & $\%$ & $75.0 \%$ & $0.0 \%$ & $0.0 \%$ & $25.0 \%$ & $100.0 \%$ \\
\hline \multirow{2}{*}{$26-35$} & Count & 13 & 0 & 0 & 0 & 13 \\
\cline { 2 - 7 } & $\%$ & $100.0 \%$ & $0.0 \%$ & $0.0 \%$ & $0.0 \%$ & $100.0 \%$ \\
\hline \multirow{2}{*}{$36-45$} & Count & 48 & 1 & 5 & 6 & 60 \\
\cline { 2 - 7 } & $\%$ & $80.0 \%$ & $1.7 \%$ & $8.3 \%$ & $10.0 \%$ & 23 \\
\hline \multirow{2}{*}{$46-55$} & Count & 22 & 0 & 0 & $4.3 \%$ & $100.0 \%$ \\
\cline { 2 - 7 } & $\%$ & $95.7 \%$ & $0.0 \%$ & $0.0 \%$ & $\mathbf{8}$ & $\mathbf{1 0 0}$ \\
\hline \multirow{2}{*}{ Total } & Count & $\mathbf{8 6}$ & $\mathbf{1}$ & $\mathbf{5}$ & $\mathbf{8 . 0 \%}$ & $\mathbf{1 0 0 . 0 \%}$ \\
\cline { 2 - 7 } & \% & $\mathbf{8 6 . 0} \%$ & $\mathbf{1 . 0 \%}$ & $\mathbf{5 . 0 \%}$ & & 1 \\
\hline
\end{tabular}

Table 2: Distribution of cases as per menstrual disorder and thyroid dysfunction.

\begin{tabular}{|c|c|c|c|c|c|c|}
\hline \multirow{2}{*}{ Chief complaints } & & \multicolumn{5}{|l|}{ S. TSH } \\
\hline & & Euthyroid & Hyperthyroid & Over hypothyroid & Subclinical hypothyroid & Total \\
\hline \multirow{2}{*}{$\begin{array}{l}\text { Continuous } \\
\text { bleeding }\end{array}$} & Count & 2 & 0 & 0 & 0 & 2 \\
\hline & $\%$ & $2.3 \%$ & $0.0 \%$ & $0.0 \%$ & $0.0 \%$ & $2.0 \%$ \\
\hline \multirow{2}{*}{ Menorrhagia } & Count & 50 & 0 & 2 & 2 & 54 \\
\hline & $\%$ & $58.1 \%$ & $0.0 \%$ & $40.0 \%$ & $25.0 \%$ & $54.0 \%$ \\
\hline \multirow{2}{*}{ Metrorrhagia } & Count & 14 & 0 & 1 & 1 & 16 \\
\hline & $\%$ & $16.3 \%$ & $0.0 \%$ & $20.0 \%$ & $12.5 \%$ & $16.0 \%$ \\
\hline \multirow{2}{*}{ Polymenorrhagia } & Count & 14 & 1 & 1 & 4 & 20 \\
\hline & $\%$ & $16.3 \%$ & $100.0 \%$ & $20.0 \%$ & $50.0 \%$ & $20.0 \%$ \\
\hline \multirow{2}{*}{ Polymenorroea } & Count & 6 & 0 & 1 & 1 & 8 \\
\hline & $\%$ & $7.0 \%$ & $0.0 \%$ & $20.0 \%$ & $12.5 \%$ & $8.0 \%$ \\
\hline \multirow{2}{*}{ Total } & Count & 86 & 1 & 5 & 8 & 100 \\
\hline & $\%$ & $100.0 \%$ & $100.0 \%$ & $100.0 \%$ & $100.0 \%$ & $100.0 \%$ \\
\hline
\end{tabular}

Table 3: Distribution of cases as per diagnosis and thyroid dysfunction.

\begin{tabular}{|c|c|c|c|c|c|c|}
\hline \multirow[b]{2}{*}{ Diagnosis } & & \multicolumn{5}{|c|}{ Thyroid dysfunction } \\
\hline & & Eu-thyroid & Hyper-thyroid & $\begin{array}{l}\text { Overt } \\
\text { hypothyroid }\end{array}$ & $\begin{array}{l}\text { Subclinical } \\
\text { hypothyroid }\end{array}$ & $\begin{array}{l}\text { Total thyroid } \\
\text { dysfunction }\end{array}$ \\
\hline \multirow{2}{*}{ Polyp } & Count & 11 & 0 & 0 & 0 & 0 \\
\hline & $\%$ & $100.0 \%$ & $0.0 \%$ & $0.0 \%$ & $0.0 \%$ & $0.0 \%$ \\
\hline \multirow{2}{*}{ Adenomyosis } & Count & 18 & 0 & 1 & 0 & 1 \\
\hline & $\%$ & $94.7 \%$ & $0.0 \%$ & $5.3 \%$ & $0.0 \%$ & $5.3 \%$ \\
\hline \multirow{2}{*}{ DUB } & Count & 23 & 1 & 2 & 7 & 10 \\
\hline & $\%$ & $69.7 \%$ & $3.0 \%$ & $6.1 \%$ & $21.2 \%$ & $30.3 \%$ \\
\hline \multirow{2}{*}{$\begin{array}{l}\text { Endometrial } \\
\text { hyperplasia }\end{array}$} & Count & 1 & 0 & 0 & 0 & 0 \\
\hline & $\%$ & $100.0 \%$ & $0.0 \%$ & $0.0 \%$ & $0.0 \%$ & $0.0 \%$ \\
\hline \multirow{2}{*}{ Fibroid } & Count & 29 & 0 & 1 & 1 & 2 \\
\hline & $\%$ & $93.5 \%$ & $0.0 \%$ & $3.2 \%$ & $3.2 \%$ & $6.5 \%$ \\
\hline \multirow{2}{*}{$\begin{array}{l}\text { Fibroid }+ \\
\text { adenomyosis }\end{array}$} & Count & 4 & 0 & 1 & 0 & 1 \\
\hline & $\%$ & $80.0 \%$ & $0.0 \%$ & $20.0 \%$ & $0.0 \%$ & $20.0 \%$ \\
\hline \multirow{2}{*}{ Total } & Count & 86 & 1 & 5 & 8 & 14 \\
\hline & $\%$ & $86.0 \%$ & $1.0 \%$ & $5.0 \%$ & $8.0 \%$ & $14.0 \%$ \\
\hline
\end{tabular}

As per above (Table 3) in DUB $21.2 \%$ cases had subclinical hypothyroidism and $6.1 \%$ had overt hypothyroidism. It was observed that $14 \%$ had thyroid dysfunction, among which $71.4 \%$ (10 out of 14) of 
thyroid dysfunction was seen in non-structural causes of AUB and $23.6 \%$ (4 out of 14) of thyroid dysfunction was observed in structural causes of AUB. Among structural causes, leiomyoma is associated with $6.5 \%$ of thyroid dysfunction, of which $3.2 \%$ of patients have subclinical hypothyroidism.

\section{DISCUSSION}

\section{Age wise distribution}

In our clinical study, AUB was commonly seen among 41-45 years of age group (31\%). Madhura et al reported $56.8 \%$ belonged to age group of 41-50 years. ${ }^{8}$ Similarly, the study conducted by Abdullah et al, showed $33.1 \%$ cases of AUB in $5^{\text {th }}$ decade which coincides with the present study. ${ }^{9}$

The studies conducted by Jetley et al, and Zeeba et al, reported that $35.89 \%$ and $35.9 \%$, respectively, of cases belonged to $5^{\text {th }}$ decade and this is in concordance with our study. ${ }^{10,11}$ As per study conducted by Zeeba et al maximum patients $(35.89 \%)$ with abnormal uterine bleeding presented in age group 41-50 years closely followed by $33.22 \%$ in the age group $31-40$ years. ${ }^{11}$ This was similar to our study. The reason for increased incidence of abnormal uterine bleeding in this age group (41-50 years) may be due to the fact that these patients are in their climacteric period. As women approach menopause, cycles shorten, and often become intermittently anovulatory due to a decline in the number of ovarian follicles and their increased resistance to gonadotrophic stimulation causes decline in estradiol level, which cannot keep the normal endometrium growing.

\section{Parity status}

In the present study, majority of patients were multiparous $(87 \%)$ and nulliparous were $8 \%$, similar to the report by Pilli et al, where in $87 \%$ of the patients were multiparous women and nulliparous women were only $7 \% .^{12}$

\section{Presenting complaints}

In our study maximum cases were seen with complaints of menorrhagia (54\%). Minimum were seen in polymenorrhoea $(8 \%)$. This is similar to study done by Patil et al where menorrhagia $(54.66 \%)$ was the most common clinical presentation followed by polymenorrhagia (28\%). ${ }^{13}$ Menorrhagia was also found to be a common clinical presentation in most of the previous studies by Nargis et al (52\%), Pillai (46.4\%) and Jetley et al, $(46.4 \%) .^{10,14,15}$

\section{Etiology}

Most common cause of AUB was DUB (33\%). Among the other organic pathological causes, fibromyoma (31\%) was the commonest cause followed by adenomyosis (19\%). Study done by Mahapatra M et al, showed DUB $(42.9 \%)$ as the most common cause of AUB followed by fibroid $(26.5 \%)$ and adenomyosis $(12 \%)$ similar to our study. ${ }^{16}$ As per the study of Madhura et al DUB (47.7\%) is the most common cause of AUB followed by fibroid $(16.1 \%)$ and adenomyosis $(8 \%) .{ }^{17}$ Fibroids are common finding in women with menorrhagia. Menorrhagia in fibroids is due to increased size of the uterine cavity which increases the surface area of the endometrium, hyperestrogenemia causing endometrial hyperplasia, vascular alteration of the endometrium and obstetric effect of fibroid on uterine vasculature leading to congestion in the endometrium. ${ }^{13}$ Endometrial hyperplasia was the least common cause but identification of endometrial hyperplasia is important because they are thought to be precursors of endometrial carcinoma.

\section{Histopathological studies}

Proliferative endometrium was found in most cases $(53.1 \%)$. This finding of proliferative endometrial change as a leading cause of AUB is comparable to studies by Anuradha Salvi et al (37.2\%) and Agrawal et al. ${ }^{18,19}$ Proliferative endometrium was the commonest finding in Khare et al and Saera et al, too. ${ }^{2,20}$

\section{Thyroid dysfunction}

Our study shows sub clinical hypothyroid present in $8 \%$ of cases, profound hypothyroid without any symptoms was present in only $5 \%$ of cases. $1 \%$ of cases had hyperthyroidism. This is similar to study conducted by Bhavani et al. ${ }^{21}$ In that $10 \%$ cases belonged to category of subclinical hypothyroidism, overt hypothyroidism $7.5 \%$ and $1.5 \%$ had hyperthyroidism. According to study by Rani et al maximum number of patients with AUB belongs to the category of hypothyroidism (19\%) and hyperthyroidism in $2 \%$ cases. $^{22}$ Kaur et al observed in their study that $85 \%$ of the patients with abnormal uterine bleeding were euthyroid, $14 \%$ hypothyroid and $1 \%$ hyperthyroid. ${ }^{23}$ Sangeeta Pahwa et al observed in their study that $22 \%$ of cases were hypothyroid, $2 \%$ hyperthyroid and $76 \%$ euthyroid. ${ }^{24}$ Maximum number of apparently normal patients with abnormal uterine bleeding belong to category of sub clinical hypothyroid. One of the explanations is the activity of thyroid is that closely linked with the process of ovarian maturation. The thyroid gland is itself dependent on direct and indirect stimulation from the ovary to discharge its own function

\section{Age-wise distribution and thyroid dysfunction}

Maximum cases with thyroid dysfunction were seen in the age group of 16-25 years. Whereas in a study done by Verma SK et al hypothyroidism was more common in age group of $31-40$ years $(38.4 \%)$ and $41-50$ years $(41 \%) .^{25}$ 


\section{Presenting complaints in thyroid dysfunction}

In this study, it was found that the occurrence of polymenorrhagia $(38.4 \%)$ in hypothyroid women is high followed by menorrhagia $(30.7 \%)$. In a study by weeks $\mathrm{AD}, 56 \%$ had menstrual disturbances and the most common complaint was menorrhagia $(36 \%){ }^{26}$

\section{Diagnosis and thyroid dysfunction}

It was observed that $14 \%$ had thyroid dysfunction, among which $71.4 \%$ (10 out of 14) of thyroid dysfunction was seen in non-structural causes of AUB and 23.6\% (4 out of 14) of thyroid dysfunction was observed in structural causes of AUB. The results are comparable to study done by Bhavani et al, where $19 \%$ (38 cases out of 200) had thyroid dysfunction, among which $76.3 \%$ (29 out of 38) of thyroid dysfunction was seen in nonstructural causes of AUB and 23.6\% (9 out of 38) of thyroid dysfunction was observed in structural causes of AUB. ${ }^{21}$

\section{CONCLUSION}

Histopathological evaluation of the curettage specimen is necessary in identifying the cause of abnormal uterine bleeding in the perimenopausal age group because of increased incidence of intrauterine lesions in this age group while in younger age groups, changes associated to hormonal effects seems to be more common.

Endometrial sampling is a safe and effective diagnostic step in evaluation of abnormal uterine bleeding after ruling out medical causes. It has several advantages over other available diagnostic methods like ultrasonography, hormonal assay, hysteroscopy and hysterosalpingography.

Accurate analysis of endometrial sample is the key to effective therapy and rational approach to treatment of women with abnormal uterine bleeding.

Abnormal uterine bleeding is frequently seen to be associated with thyroid dysfunction and in majority of the patients menstrual abnormality may even precede the occurrence of other clinical signs and symptoms of thyroid dysfunction. Hence, thyroid assessment is necessary in such cases.

\section{Funding: No funding sources}

Conflict of interest: None declared

Ethical approval: The study was approved by the Institutional Ethics Committee

\section{REFERENCES}

1. Dangal G. A study of endometrium of patients with abnormal uterne bleeding at Chitwan valley. Kathmandu Univer Med J. 2003;1:110-2.

2. Khare A, Bansal R, Sharma S. Morphological spectrum of endometrium in patients presenting with dysfunctional uterine bleeding. People's J Sci Res. 2012;5(2):13-6.

3. Livingstone M, Fraser IS. Mechanisms of abnormal uterine bleeding. Human Repro Update. 2002;8(1):60-7.

4. Munro MG, Critchley HO, Broder MS, Fraser IS. FIGO classification system (PALM-COEIN) for causes of abnormal uterine bleeding in nongravid women of reproductive age. Int J Obstet Gynaecol. 2011;113(1):3-13.

5. National Collaborating Center for women's and Children's Health, National Institute of Clinical Excellence. Heavy menstrual bleeding. Clinical guideline. London : RCOG Press; 2007.

6. DeVORE GR, Owens OD, Kase NA. Use of intravenous Premarin in the treatment of dysfunctional uterine bleeding- a double-blind randomized control study. Obstet Gynecol. 1982;59(3):285-91.

7. Munro MG, Mainor N, Basu R, Brisinger $\mathrm{M}$, Barreda L. Oral medroxyprogesterone acetate and combination oral contraceptives for acute uterine bleeding: a randomized controlled trial. Obstet Gynecol. 2006;108:924-9.

8. Damle RP, Dravid NV, Suryawanshi KH, Gadre AS, Bagale PS, Ahire N. Clinicopathological spectrum of endometrial changes in peri-menopausal and postmenopausal abnormal uterine bleeding: A 2 years study. J Clin Diagnost Res. 2013;7(12):2774.

9. Abdullah LS, Bondagji NS. Histopathological pattern of endometrial sampling performed for abnormal uterine bleeding. Bahrain Med Bull. 2011;33(4):1-6.

10. Jetley S, Rana S, Jairajpuri ZS. Morphological spectrum of endometrial pathology in middle aged women with atypical uterine bleeding - a study of 219 cases. J Midlife Health. 2013;4:216-20.

11. Jairajpuri ZS, Rana S, Jetley S. Atypical uterine bleeding-Histopathological audit of endometrium A study of 638 cases. Al Ameen J Med Sci. 2013;6(1):21-8.

12. Pilli GS, Sethi B, Dhaded AV, Mathur PR, Dysfunctional uterine bleeding. J Obstet Gynaecol India. 2001;52(3):87-9.

13. Patil CS. A study of clinical correlation with histopathological diagnosis of abnormal uterine bleeding MedPulse. Int Med J. 2016;3(7):697-9.

14. Nargis N, Karim I, Sarwar KB. Abnormal uterine bleeding in perimenopausal age: different causes and its relation with histopathology. Bangl J Med Sci. 2014;13(2):135-9.

15. Pillai SS. Sonographic and histopathological correlation and evaluation of endometrium in perimenopausal women with abnormal uterine bleeding. Int J Reprod Contracept Obstet Gynecol. 2014;3:113-7.

16. Mahapatra M, Mishra P. Clinicopathological evaluation of abnormal uterine bleeding. J Health Res Rev. 2015;2(2):45. 
17. Banale M. Clinicopathological spectrum of endometrial changes in abnormal uterine bleeding. Sch J App Med Sci. 2015;3(9A):3168-72.

18. Salvi A, Mital P, Hooja N, Batar A, Soni P, Beniwal R. Spectrum of endometrial histopathology in women presenting with abnormal uterine bleeding. Parity. 2015;1(2):3.

19. Agrawal S, Mathur A, Vaishnav K. Histopathological study of endometrium in abnormal uterine bleeding in women of all age groups in western rajasthan (400 cases). Int J Basic Appl Med Sci. 2014;4(3):15-8.

20. Afghan S, Yasmeen A. Abnormal uterine bleeding (AUB) a clinicopathological study of 150 cases. Ann Pak Inst Med Sci. 2013;9(4):201-4.

21. Bhavani N, Avanthi S, Aradhana G, Sangeeta C, Prasannakumar VS. A study of correlation between abnormal uterine bleeding and thyroid dysfunction. Int J Recent Trends Sci Tech. 2015;14(1):131-5.

22. Rani. Study of hypothyroidism in women with abnormal uterine bleeding. J Dent Med Sci 2016;15(4):12-8.
23. Kaur T, Aseeja V, Sharma S. Thyroid dysfunction in dysfunctional uterine bleeding. Webmed Central Obstet Gynaecol. 2011;2(9):002235.

24. Pahwa S, Shailja G, Jasmine K. Thyroid dysfunction in dysfunctional uterine bleeding. J Adv Res Bio Sci. 2013;5(1):78-83.

25. Verma SK, Pal A, Jaswal S. A study of thyroid dysfunction in dysfunctional uterine bleeding. Int $\mathbf{J}$ Reprod Contracept Obstet Gynecol. 2017;6:2035-9.

26. Weeks AD. Correlating menstrual irregularities with levels of thyroid hormone deficiency. BMJ. 2000;320(7235):649.

Cite this article as: Yeole N, Nayak AH, Mehendale M. Study of etiopathogenesis and clinical profile of patients presenting with abnormal uterine bleeding. Int J Reprod Contracept Obstet Gynecol 2020;9:70-6. 